\title{
Percepções sobre o autismo sob a ótica das mães
}

\section{Perception about autism under the optics of mothers}

\author{
Debora Biffi' $\bullet$ Aline Mellos ${ }^{2} \bullet$ Vinícius Rodrigues Ribeiro ${ }^{2} \bullet$ Luana Daudt Pereira $^{2} \bullet$ Francisco Dias Manzoni $^{3}$
}

\begin{abstract}
RESUMO
Introdução: O transtorno do espectro autista é classificado como um distúrbio agressivo do desenvolvimento. Este compromete todo o desenvolvimento neurológico, e se caracteriza pelo desequilíbrio comportamental exposto pela inaptidão na inclusão social. Objetivo: Analisar as percepções e experiências emocionais de mães com filhos diagnosticados com transtornos do espectro autista. Metodologia: Estudo de caráter qualitativo, que teve como público alvo mães de filhos com diagnóstico de transtorno do espectro autista, participantes das APAEs. Foi realizada uma entrevista semi-estruturada gravada por gravador digital, e posteriormente transcrita. Resultados: Notoriamente as mães possuem dificuldades para compreender e se adaptar a realidade do filho diagnosticado de autismo. Criam expectativas e perspectivas quanto ao futuro dos filhos almejando que estes desenvolvam prioritariamente a independência. Considerações Finais: Obtivemos a possibilidade de compreender melhor as expectativas e as dificuldades das mães das crianças com diagnóstico de TEA. Foi encontrado idade média para o diagnóstico de espectro autista do filho entre 3 anos e 4 meses.A descoberta do diagnóstico do TEA causou importantes sentimentos prejudiciais e de não aceitação à essas mães. Surgem sentimentos negativos, afetando assim a saúde mental dessas mães e familiares.
\end{abstract}

Palavras-chave: Autismo; Psicodinâmica; Percepção.

\begin{abstract}
Introduction:Autism spectrum disorder is classified as an aggressive developmental disorder.This compromises the entire neurological development and is characterized by the behavioral imbalance exposed by the inaptitude in social inclusion. Objective:To analyze the perceptions and emotional experiences of mothers with children diagnosed with autism spectrum disorders. Methodology: This was a qualitative study that had the target audience of mothers of children diagnosed with autism spectrum disorder, who participated in APAEs.A semi-structured interview was recorded by digital recorder, and later transcribed. Results: Notoriously, mothers have difficulties in understanding and adapting the reality of a child diagnosed with autism. They create expectations and perspectives on the future of children, aiming for them to develop independence first. Final Considerations:We obtained the possibility to better understand the expectations and difficulties of the mothers of children diagnosed with ASD. We found a mean age for the diagnosis of autistic spectrum of the child between 3 years and 4 months. The discovery of the diagnosis of ASD has caused important feelings of detriment and non -acceptance to these mothers. Negative feelings arise, thus affecting the mental health of these mothers and their families. Keywords: Autism; Psychodynamics; Perception.
\end{abstract}

I Professora do Centro Universitário Cenecista de Osório- UNICNEC. Doutoranda pelo PPG Ciências Médicas- UFRGS. Mestre em Enfermagem ProfissionalUNISINOS

Especialista em Saúde Mental- UNINGÁ. Especialista em Saúde da Família- UFSC

2 Enfermeiros, formados pelo Centro Universitário Cenecista de Osório- RS

3 Graduando em Enfermagem, pelo Centro Universitário Cenecista de Osório- RS 


\section{INTRODUÇÃO}

Os transtornos do espectro autista são intrigantes, do ponto de vista do conhecimento científico, e tem desafiado os pesquisadores que abordam esta temática. Em termos de definição, o autismo incide em um transtorno do neurodesenvolvimento, que se caracteriza por danos constantes na interação social, altera a comunicação e limita os padrões de desempenho e interesses. Além disso, dá-se ênfase na importância dos fatores genéticos da síndrome e com pesquisas feitas há mais de cinquenta anos, a origem da síndrome segue desconhecida, provocando dificuldade nas intervenções educativas e no tratamento ${ }^{(1)}$.

Trata-se de uma situação que desencadeia modificações no âmbito familiar devido às condições de acompanhamento para que a criança se desenvolva. Os transtornos do espectro autista compõem uma posição de impacto, podendo refletir diretamente na rotina do dia -a-dia, na readaptação das tarefas e causa diversas modificações nas relações familiares. Diante ao momento da manifestação da doença ou síndrome crônica, como exemplo o transtorno de espectro autista (TEA), a família geralmente passa por diversos estágios, a saber: impacto, negação, luto, enfoque externo e encerramento, onde estão associados a emoções complexas e confusas (2).

Visto que os pais são os primeiros a notarem que seus filhos manifestam comportamentos diferentes, que fogem do padrão normal, é de extrema importância o papel destes no diagnóstico do transtorno autista. Diante dessa situação, manifestam-se sentimento de impotência e angústia, por não saber como ajudar seus filhos.A fragilidade dos serviços de saúde, assim como os profissionais não preparados para reconhecer o autismo precocemente, intensifica esses sentimentos e acaba ocasionando a demora e não definição do diagnóstico(3).

Algumas mães, quando são questionadas sobre o futuro dos filhos, revelam que visam a independência deles, encorajando-os a realizar ações no dia a dia que têm esse objetivo. Elas idealizam que estes sejam realizados em sua vida amorosa e tenham um emprego. Como não sabem o futuro dos filhos, algumas dessas mães têm medo da morte, outras acreditam que algum familiar assumirá o compromisso de cuidar desse individuo portador de autismo após a sua partida ${ }^{(4)}$.

Em vista disso, esta pesquisa pretende levantar dados sobre as situações e experiências vividas por mães com filhos portadores de TEA.A partir das informações levantadas, os profissionais terão uma oportunidade melhor de refletir, buscar novas diretrizes para o desenvolvimento de uma terapêutica relevante para todo o núcleo familiar.Também será possível identificar as dificuldades e definir prioridades para serem desenvolvidas com a família dessas mães.

\section{METODOLOGIA}

Trata-se de uma pesquisa qualitativa-exploratória, de abordagem descritiva na qual foi realizada através de um questionário semi estruturado. Realizada com grupos de mães de crianças que possuem filhos com diagnóstico de transtorno do espectro autista, provenientes das Associações de Pais e Amigos Especiais -APAE localizadas na cidade de Capão da Canoa e Tramandaí/RS. Como participantes do estudo tivemos mães que participam ativamente de grupos realizados nas APAEs, com objetivo de dividir suas experiências e procurem estes grupos para apoio e enfrentamento a partir do diagnóstico de Transtorno de Espectro Autista dos filhos.

Foram entrevistadas 20 mães, sendo 10 da APAE do município de Capão da Canoa e 10 mães do município de Tramandaí. Como critérios de inclusão: mães com filhos diagnosticados com Transtornos do Espectro que estejam envolvidas em grupos nas APAEs supracitadas e estas aceitaram assinar o Termo de Consentimento Livre e Esclarecido- TCLE. As entrevistas semiestruturadas foram gravadas com gravador digital, e logo após foram transcritas com o mínimo de interferência dos pesquisadores.

O anonimato dos participantes desse estudo será garantido, prevenindo julgamentos ou pré-conceitos, respeitando sua privacidade segundo a resolução n466/2012 do Conselho Nacional de Saúde do Ministério da Saúde ${ }^{(5)}$.Como instrumento de preservação do anonimato, os nomes dos participantes foram substituídos por letras. Para a análise dos dados, foi utilizado o método de Glase, o qual objetiva compreender o mundo em qual se vive, tendo como base as subjetividades das experiências e seus significados individuais ${ }^{(6)}$. Para meIhor análise e discussões, estas foram divididas em categorias: O Diagnóstico e o Sentimento e As Dificuldades e Perspectivas de Futuro.

\section{RESULTADOS}

Foram entrevistadas para o desenvolvimento desta pesquisa mães participantes dos grupos de apoio da Associação de Pais e Amigos Especiais dos municípios de Capão da Canoa e Tramandaí que tenham filhos com diagnóstico de Transtorno do Espectro Autista. A média de idade das mães entrevistadas foi de 35,3anos, tendo a mais nova 22 anos e a mais velha 47 anos. Referente ao grau de estudo 7(sete) possuíam ensino fundamental incompleto, 8(oito) possuem o ensino completo e 4 possuem ensino superior. Em relação ao estado civil II (onze) mães são casadas e 8(oito) mães são solteiras.

As mães entrevistadas desenvolviam as seguintes atividades laborais: administradora, enfermeira, cabeleireira, vigilante, artesã, maquiadora, extencionista rural, professora, corretora de imóveis e 8(oito) do lar e faxineira. 
Para assegurar o anonimato nos usuários estes foram identificados por letras e números ao final de cada fala apresentada no decorrer do texto, bem como o nome das crianças envolvidas quando citados no decorrer do texto foram substituídos por letras. As questões feitas às mesmas foram agrupadas em categorias para melhor análise e discussão dos resultados encontrados a partir das transcrições das entrevistas.

\section{O diagnóstico e o sentimento:}

Conforme os critérios diagnósticos do DSM- $5^{(7)}$, as primeiras manifestações do TEA devem aparecer antes dos 36 meses de idade. Todavia, dados empíricos demonstram que a maioria das crianças apresenta problemas no desenvolvimento entre os 12 e 24 meses, sendo que alguns desvios qualitativos no desenvolvimento aparecem antes mesmo dos 12 meses. Porém, alguns estudos têm demonstrado que crianças com TEA dificilmente recebem esse diagnóstico antes dos 5 anos, sendo que algumas são diagnosticadas apenas quando atingem idade escolar ${ }^{(8)}$. Para podermos observar e verificar de modo mais claro questionamos as mães quanto a idade de diagnóstico de seus filhos.

Ele...saiu o diagnostico dele quando ele tinha 8 anos. (M03)

Eu acho que ele foi diagnosticado com autismo ele devia ter uns três anos e meio por aí, quatro anos, aos dois anos e meio a gente começou a busca pelo diagnostico. (M06)

É eu descobri, suspeitei com cerca de 4 anos, mas o diagnóstico mesmo, ele já tinha 5 anos de idade. (M08)

Ai, a gente levava ela bastante tempo nos hospitais, essas coisas, mas já mais ou menos sabia né, mas demoro um tempo, depois de vários exames, várias coisas a gente fizeram nela, e nenhum médico dizia nada, sempre dizia que ela era normal, não tinha nada, só que daí depois a gente levou já na especialista mesmo né, a neuropediatra, ela já deu o laudo de autista daí, mas daí com oito anos né, isso ela tinha oito anos. (M/4) Ela tinha dois anos e meio. (M/8)

Com base nos relatos das mães foi encontrado uma idade média para o diagnóstico de espectro autista do filho de 3 anos e 4 meses, sendo o mais novo diagnosticado com 20 dias e o mais velho com 8 anos. Este diagnóstico ocorreu inicialmente a partir da percepção das mães sobre o comportamento dos filhos, com enfoque principalmente na questão do desenvolvimento da fala e no andar, que alavancou a desconfiança e curiosidade das mesmas para investigar o diagnóstico do filho. A descoberta precoce do diagnóstico se faz importante na questão da possibilidade imediata de intervenções, de suma importância, visto que os resultados positivos de respos- tas à terapias são mais relevantes e efetivos quando iniciados precocemente.

O diagnóstico de TEA de um filho, vem sendo descrito na literatura por diversos autores como razão de frustração eestresse materno excessivo, bem como a dificuldade na comunicação de seus desejos, experimentam assim, constantemente tais sentimentos. De acordo com Malagris ${ }^{(9)}$ estes sentimentos podem originar estresse crônico, se muito presentes na vida das pessoas. Além do sentimento de frustração, comumente experimentado por essas mães, diversas são as causas associadas ao predomínio do estresse materno, pelo fato de serem as principais cuidadoras dessas crianças ${ }^{(10)}$. Quando questionamos as mães sobre qual o sentimento delas referentes aos filhos, obtivemos os seguintes relatos:

"O primeiro sentimento que eu tive quando eu descobri que ele era autista foi... um sentimento de confusão assim, de me sentir perdida, não saber o que que eu ia fazer, como que ia ser, como que eu ia proceder, pra onde é que eu ia, o que que eu ia fazer, um sentimento assim de confusão, mas depois passou, foi passando, com o tempo foi vindo a aceitação e procurando ajuda pra melhor tratamento dele" (MOI)

"Angustia, tristeza, medo, os primeiros sentimentos foram esses." (M06)

"É.. Sentimento de luto né, que pelo que a gente sabe de autismo, e eu não sabia nada, comecei a pesquisar, é uma síndrome que vai ser pro resto da vida assim né, ele vai ser autista pra sempre, então é o sentimento de luto, nos primeiros dias eu chorei dois dias, dois dias eu chorei sem parar, ai depois eu bom, tem que aceitar depois né veio todo aquele processo né deaceitação.Negação em alguns momentos que a gente até suspeita e passei por vários profissionais e alguns me disseram que ele não era autista, aiaté tu chegar no diagnóstico de verdade assim, com confiança, momentos de negação, mas depois fui atrás né, comecei $a$ ir atrás de pessoas que também tem filhos autistas aqui em capão e comecei a ir atrás de tratamento." (M08) "Foi preocupação com ele no futuro, na fase da adolescência e da vida adulta." (M/9)

A partir dos relatos percebe-se então que em todas as entrevistadas vivenciam sentimentos que lhe causam danos emocionais, tais como: confusão, frustração, luto, angustia, tristeza, medo, preocupação e até alivio pela descoberta do diagnóstico.A maioria destes sentimentos pode abalar a saúde mental das mães e famílias, ocasionando assim estresse crônico e dificuldade para aceitar e lidar com o próprio filho. Identificar os sentimentos que as mães desenvolvem durante o cuidado aos filhos é de suma importância para que o cuidado posso também ser fornecido a elas, que são peças fundamentais nesse processo tão complexo. Poder desenvolver uma escuta 
qualificada para a mãe e familiares nos permite prestar uma assistência digna a estas em suas dificuldades.

\section{As dificuldades e perspectivas de futuro:}

As Famílias que possuem filhos com transtorno do espectro autista, vivenciam dificuldades em todos os aspectos da vida cotidiana, as dificuldades iniciam quando buscam compreender o que há de errado com a criança, porquê do seu comportamento ser diferente dos demais. Para os pais é difícil identificar o se o quadro que o filho apresenta é específico de alguma doença ou se é apenas um comportamento da própria criança ${ }^{(11)}$.As mães quando questionadas sobre quais as maiores dificuldades encontradas no dia a dia do seu filho, relataram o seguinte:

"A maior dificuldade que eu vejo é a agitação dele, que ele é muito agitado, tem que tá o tempo todo de olho nele, não consigo nem dormir as vezes direito, por causa da agitação, mais ã.... fora isso é tranquilo, ele é muito carinhoso, só tem que está cuidando a agitação dele que ele mexe em tudo." (MOI)

"A em tudo, aonde tu vai, o jeito que as pessoas te recebem, os olhares, tudo..." (M05)

"As maiores dificuldades são... uma delas entender ele, saber o que ele ta querendo dizer, satisfaze também, ã o que ele quer e trabalha o desenvolvimento né, não perde nenhuma oportunidade de desenvolver o que ele tem, o potencial que ele tem" (M06)

"É a comunicação, a falta de comunicação, essa é a maior dificuldade porque ela não consegue transmitir o que ela tá sentindo o que ela pensa, a gente tenta adivinhar e nem sempre se consegue, então é uma repetição muito grande do que ela fala do que ela transmite, ela tem o conhecimento de uma meia dúzia de palavras mais ou menos, mas essa meia dúzia de palavras a gente tenta ter um diálogo, mas conseguimos, ela se comunica, ela, má muito precariamente." (M/2).

O cuidado de uma criança autista requer muito dos pais ou cuidadores, saber entender, ser paciente, ter atenção são algumas das estratégias para conseguir lidar com esse dever que em seu caminho possui muitas dificuldades, a partir dos relatos percebe-se que ainda existe preconceito e falta de entendimento sobre o TEA por parte da sociedade. Relatam-se dificuldades variadas, e além das dificuldades por conta de pressões externas, a sociedade ainda tem muita dificuldade em conviver com as diferenças, o que se torna o principal conflito sofrido pelos familiares da criança autista, que é o preconceito.

A literatura descreve que a maior preocupação das mães a respeito do futuro do filho autista diz respeito à necessidade de responsabilidade pelos cuidados do mesmo, mas que ao mesmo tempo almejam a independência do filho e incentivam ações no cotidiano dos mesmos para isso ${ }^{(12)}$. Com os relatos sobre a expectativa sobre o futuro dos filhos, seguem as falas:

“Olha, no início eu não acreditava que ele podia ser independente, ter uma profissão né, mas hoje com toda ajuda que eu to tendo né com de profissionais, com conhecidos que nem agora a gente tem o grupo do AMA né, a gente consegue se unir bastante pra ajudar eles em tudo, então agora eu to acreditando que ele pode ter o futuro melhor, tipo de repente até conseguir um emprego, sabe, se independente, através de muita luta que a gente vai correndo atrás né, então é só se dedicar ir atrás, ajuda de profissionais né, eles conseguem sim." (M03)

"Bom, eu... eu faço tudo que eu posso fazer hoje, no momento ele tem, ele está tendo os tratamentos necessários assim...Que eu posso pagar óbvio né, ele tem um apoio extraescolar assim, particular de uma psicopedagoga, que é onde ele aprende mais, que na escola é bem difícil ele aprender.Porque eu não tenho grande expectativa e ao mesmo tempo eu, eu sonho com a autonomia dele, o meu objetivo principal é que ele tenha o máximo de autonomia possível, então isso aí..." (M08)

"A única coisa que eu quero, que seja feliz, não importa o que ela vai saber, se ela vai saber ler se não vai ler, se vai estudar se ela vai é, só ser feliz, e ela é uma criança alegre, uma criança feliz, naquilo que ela tem, naquilo que ela consegue, porque ela tá agora procurando $a$ independência dela, ela é dinâmica, ela é $a$ santa diva, gosta de desenhar, gosta de pinta, gosta de escrever apesar de não ser alfabetizada mas já, algumas letrinhas ela escreve, ela gosta de assistir vídeos, dançar, não muito por causa da motora, que agora começou a ser desenvolvida a motora fina aos quatorze anos só a motora fina começou a se desenvolver, tão o importante pra nós é só que ela seja feliz." (M/2) "Um homem crescido, trabalhador, estudado se formado, tendo a família dele a esposa dele, os filhos dele, e servindo a Deus em primeiro lugar, que é o que eu to tentando levar pro caminho de Deus, então é, espero que Deus realize meu sonho, tocando um, um instrumento dentro da igreja, com a família dele e os filho dele, é o meu desejo maior, se Deus realizar esse desejo não precisa realizar mais nada (rs). "(M/9)

Pode-se perceber com os relatos que a experiência da maternidade, enquanto se tem um filho autista, torna-se uma vivência complexa e cheia de desafios para as mulheres, uma vez que se encontram com o inesperado e desconhecido, sobre o futuro existem algumas expectativas, no entanto muitas incertezas, e por causa disso, algumas mães acabam por ter mais dificuldades de planejamento para com o seu futuro e até mesmo o da criança autista. 


\section{CONCLUSÃO}

A partir desta pesquisa observou-se que as crianças portadoras de autismo receberam diagnóstico com uma média de idade de aproximadamente de 3 anos, idade considerada usual pela literatura. $O$ diagnóstico precoce gera uma possibilidade de planejamento e utilização de serviços educacionais para o melhor desenvolvimento desta criança e amparo as demandas das famílias.

A descoberta do diagnóstico do TEA causou importantes sentimentos prejudiciais e de não aceitação à essas mães. Este fato tem reflexo direto no cotidiano e no contexto familiar, quanto a expectativa do filho as mães enfrentam um sentimento de frustração. Surgem sentimentos negativos, afetando assim a saúde mental dessas mães e familiares, o que acaba gerando uma aceitação por muitas vezes tardia, podendo prejudicar o desenvol- vimento do filho e a relação mãe e filho. Percebeu-se que alguma mudança na rotina especialmente por parte das mães ocorreu com todas entrevistadas, principalmente no que diz respeito a difícil socialização da criança e aceitação por parte da sociedade.

As dificuldades de relacionamento e interação do filho, levam essas mães, muitas vezes, a não saírem mais com os filhos, evitando ambientes sociais, especialmente para evitar demonstrações de preconceito com relação à criança e seu comportamento. Ainda que as mães não possam prever o futuro dos filhos notou-se que a maioria das mães visam a independência e felicidade dessa criança. $E$ que apesar das limitações dessas crianças, todas possuem algum tipo de suporte educacional e terapêutico, ainda que muito frágil, contribui para o desenvolvimento, para futuramente alcançarem sua independência e aceitação na sociedade. 


\section{REFERÊNCIAS}

I) LouretoGDL, Moreno SR. As relações fraternas no contexto do autismo: um estudo descritivo. Revista Psicopedagogia [Internet]. 2016 [acesso em: 17 de setembro de 2017];102(33):307-318. Disponível em: http:// pepsic.bvsalud.org/scielo.php?script=sci_arttext\&pi$d=S 0103-84862016000300009$

2)Pinto RNM, Torquato IMB, Collet N, Reichert APS, Souza NVL, Saraiva AM. Autismo infantil: impacto do diagnóstico e repercussões nas relações familiares. Rev Gaúcha Enferm [Internet]. 2016 [acesso em 17 de setembro de 2017]; 37(3):6I572. Disponível em:https://www.researchgate.net/ profile/Altamira_Reichert2/publication/30976/386_Revista_Gaucha_de_Enfermagem_Artigo_Original_Autismo_ infantil_impacto_do_diagnostico_e_repercussoes_nas_ relacoes_familiares_Infantile_autism_impact_of_diagnosis_and_repercussions_in_family_relationshi/links/582 Idd4c08ae5385869ffO I3.pdf

3)Zanata EA et al. Cotidiano de famílias que convivem com o autismo infantil. Revista Baiana de Enfermagem [Internet]. 2014 [acesso em:05 de agosto de 20I7]; 28(3):27I282. Disponível em:https://search.proquest.com/openview/ b79b6e0325d3dedf7e3a4 I bdc036d57b/ I ?pq-origsite=gscholar\&cbl=2040 I I 2

4)SegerenL,Françozo MFC.As vivências de mães de jovens autistas. Psicologia em Estudo [Internet], 2014 [acesso em:04 de agosto de 2017]; 19(1):34-46. Disponível em:http:// www.redalyc.org/html/287 I/287 | 32425006/

5)BRASIL. Conselho Nacional de Saúde. Resolução Número 466 , de dezembro de 2012.
6)Polit DF, Beck C.T. Fundamentos de pesquisa em enfermagem: avaliação de evidências para a prática da enfermagem. 7. ed. Porto Alegre:Artmed; 201 I.

7)American Psychiatric Association. Diagnostic and Statistical Manual of Mental Disorders, Fifth Edition (DSM-V). Arlington,VA:American Psychiatric Association, 2013.

8)Zanon, RB,BackesB,Bosa CA. Identificação dos Primeiros Sintomas do Autismo pelos Pais. Psicologia: Teoria e Pesquisa [internet], 2014 [acesso em: 13 de agosto de 2017]; I(30):25-33. Disponível em: http://www.scielo.br/scielo. php?script=sci_arttext\&pid=SO I02-377220 I 4000100004

9)Nunes, Ângela Maria F; Santos, Manoel Antônio. Itinerário terapêutico percorrido por mães de crianças com transtorno autístico. Psicol. reflex. crít., Porto Alegre, v. 23, n. 2, p. 208-22I, 2010.

10)MoxotóGFA,Malagris L EN.Avaliação de Treino de Controle do Stress para Mães de Crianças com Transtornos do EspectroAutista.Psicologia:Reflexão e Crítica [internet],20I5 [acesso em: I 3 de agosto de 20I7]; 28(4):772-779. Disponível em: http://www.redalyc.org/html/ /88//88425730 I6/

I I)CampeloLCR,CostaSME,Colvero LA. Difficulties of familes in caring for children and adolescents with mental disorders: an integrative review. Rev. esc. Enferm USP [internet], 2014 [acesso em: 20 de setembro de 2017]; 48:192198. Disponível em:http://www.scielo.br/scielo.php?pi$\mathrm{d}=$ S0080623420 I 4000700 I $92 \&$ script=sci_arttext

12) ANDRADE, Aline Abreu e; TEODORO, Maycoln Leani Martins. Família e autismo: uma revisão da literatura. Contextos Clínicos, São Leopoldo, v. 5, n. 2, dez. 2012. [acesso em: 20 de setembro de 2017]. Disponível em: http://pepsic. bvsalud.org/pdf/cclin/v5n2/v5n2a08.pdf. 